\title{
Determination of Bending Failure Load of Hat-Type Folded Composite Plate Using Finite Element Method
}

\author{
Bui Van Binh ${ }^{1^{*}}$, Tran Ich Thinh ${ }^{2}$, Tran Minh Tu $^{3}$ \\ ${ }^{1}$ University of Power Electric, Hoang Quoc Viet str., Tu Liem dist., Hanoi, Vietnam \\ ${ }^{2}$ Hanoi University of Science and Technology, No. 1 Dai Co Viet str., Hai Ba Trung dist., Hanoi, Vietnam \\ ${ }^{3}$ University of Civil Engineering, Giai Phong str., Hai Ba Trung dist., Hanoi, Vietnam \\ Received: April 8, 2020; Accepted: November 12, 2020
}

\begin{abstract}
Structural failure is initiated when a material is stressed beyond its strength limit. Determination of failure loads and failure location is one of the most important problems in design structures. This paper analyzed the failure of the hat-type laminated composite plate under a bending load. Based on the Reissner-Mindlin plate theory and isoparametric rectangular plate elements with five degrees of freedom per node, an algorithm and Matlab code were established to compute the stresses and bending failure load of the folded composite plate according to Tsai-Wu and Maximum stresses criteria. The numerical results are reliable when compared with the published results in the literature for some specific cases.
\end{abstract}

Keywords: failure analysis, folded composite plate, Tsai-Wu criterion, maximum stress criterion, Mindlin plate theory

\section{Introduction}

Nowadays, folded laminate composite plates are very useful in engineering. Their applications have been found in various branches of engineering, such as roofs, ship hulls, sandwich plate cores, and cooling towers, etc. They are lightweight, easy to form, economical, and have much higher loadcarrying capacities than flat plates, which ensured their popularity and has attracted constant research interest since they were introduced.

Investigations on isotropic folded plate analysis in static and vibration have been presented by many researchers [1-4]. And there was very limited information regarding the analysis of composite folded structures. Haldar and Sheikh [5] presented a free vibration analysis of isotropic and composite folded plate by using a sixteen nodes triangular element. Peng et al.[6] presented an analysis of folded plates subjected to bending load by the first-order shear deformation theory (FSDT) meshless method. In this, a meshfree Galerkin method based on FSDT for the elastic bending analysis of stiffened and unstiffened folded plates is analyzed. All these works are limited, they did not analyze the failure of the structure.

A number of failure criteria are the maximum stress, the maximum strain, Tsai-Hill, Tsai-Wu, Hoffman, etc. Investigations on the first-ply failure analysis of composite laminates have been put forward by many researchers. Reddy and Pandey [7] have presented a finite element procedure based on FSDT for first-ply failure analysis of laminated composite plates subjected to in-plane and/or transverse loads. Ghosh and Chakravorty presented the failure behaviour of cross and angle ply, symmetrically laminated graphite-epoxy composite shell roofs in [8]. Chen et al. [9] presented some comparisons between experimental and numerical results failure of composite box beams used in wind turbine blades. Meng et al. [10] developed a threedimensional finite element analysis to investigate the effect of fibre lay-up on the initiation of failure of laminated composites in bending. Deland et al. [11] presented the biaxial failure of woven fabric composite plates under the bending standard test. Sun et al. [12] presented some comparisons between results from three-point bending tests and finite element models based on Hashin's criteria,... However, there are no previous studies that mentioned failure analysis of folded composite plate.

In this paper, a finite element algorithm and Matlab computer code based on FSDT were built to present a stress analysis and failure analysis of the folded composite plates under bending load. The effects of folding angles and boundary conditions will be investigated. The Tsai Wu criterion and maximum stress criterion is used in failure analysis.

\footnotetext{
*Corresponding author: Tel.: (+84) 949000226

Email: binhbv@epu.edu.vn
} 


\section{Theory formulations}

\subsection{Displacement and strain field}

According to the Reissner-Mindlin plate theory, the displacements $(u, v, w)$ are referred to those of the mid-plane $\left(u_{0}, v_{0}, w_{0}\right)$ as [13]:

$$
\begin{aligned}
& u(x, y, z)=u_{0}(x, y)+z \theta_{x}(x, y) \\
& v(x, y, z)=v_{0}(x, y)+z \theta_{y}(x, y) \\
& w(x, y, z)=w_{0}(x, y)
\end{aligned}
$$

where: $\theta_{x}$ and $\theta_{y}$ are the bending slopes in the $x z$ and $y z$-plane, respectively.

The generalized displacement vector at the mid-plane can thus be defined as

$$
\{u\}=\left\{u_{0}, v_{0}, w_{0}, \theta_{x}, \theta_{y}\right\}
$$

In laminated plate theories, the membrane $\{N\}$, bending moment $\{M\}$ and shear stress $\{Q\}$ resultants can be obtained by integration of stresses over the laminate thickness. The stress resultants - strain relations can be expressed in the form:

$$
\left\{\begin{array}{l}
\{N\} \\
\{M\} \\
\{Q\}
\end{array}\right\}=\left[\begin{array}{ccc}
{\left[A_{i j}\right]} & {\left[B_{i j}\right]} & {[0]} \\
{\left[B_{i j}\right]} & {\left[D_{i j}\right]} & {[0]} \\
{[0]} & {[0]} & {\left[F_{i j}\right]}
\end{array}\right]\left\{\begin{array}{l}
\left\{\varepsilon^{0}\right\} \\
\{\kappa\} \\
\left\{\gamma^{0}\right\}
\end{array}\right\}
$$

where

$$
\begin{aligned}
& \left(\left[A_{i j}\right],\left[B_{i j}\right],\left[D_{i j}\right]\right)=\sum_{k=1}^{n} \int_{h_{k-1}}^{h_{k}}\left(\left[Q_{i j}^{\prime}\right]_{k}\right)\left(1, z, z^{2}\right) d z \\
& i, j=1,2,6 \\
& \quad[F]=\sum_{k=1}^{n} f \int_{h_{k-1}}^{h_{k}}\left(\left[C_{i j}^{\prime}\right]_{k}\right) d z \\
& \quad f=5 / 6 ; i, j=4,5
\end{aligned}
$$

$n$ : number of layers, $h_{k-1}, h_{k}$ : the position of the top and bottom faces of the kth layer.

$\left.\left[Q^{\prime}\right]_{\mathrm{j}}\right]_{\mathrm{k}}$ and $\left[C_{\mathrm{ij}}^{\prime}\right]_{\mathrm{k}}$ : reduced stiffness matrices of the $k^{\text {th }}$ layer (see [14]).

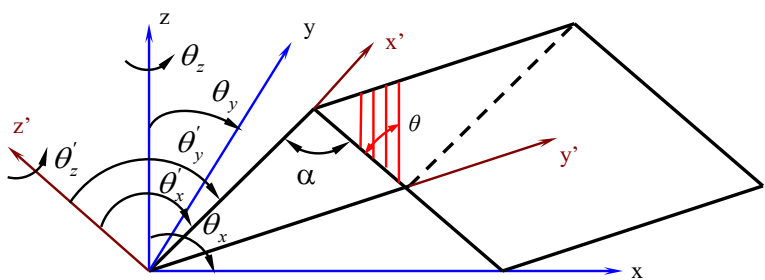

Fig. 1. Global $(\mathrm{x}, \mathrm{y}, \mathrm{z})$ and local $\left(\mathrm{x}^{\prime}, \mathrm{y}^{\prime} \mathrm{z}^{\prime}\right)$ axes system for folded plate element
In the present study, eight nodded isoparametric quadrilateral element with five degrees of freedom per nodes is used. The displacement field of any point on the mid-plane given by:

$$
\begin{aligned}
& u_{0}=\sum_{i=1}^{8} N_{i}(\xi, \eta) \cdot u_{i} ; v_{0}=\sum_{i=1}^{8} N_{i}(\xi, \eta) \cdot v_{i} ; \\
& \mathrm{w}_{0}=\sum_{i=1}^{8} N_{i}(\xi, \eta) \cdot w_{i} ; \theta_{x}=\sum_{i=1}^{8} N_{i}(\xi, \eta) \cdot \theta_{x i} ; \\
& \theta_{y}=\sum_{i=1}^{8} N_{i}(\xi, \eta) \cdot \theta_{y i}
\end{aligned}
$$

where:

$N_{i}(\xi, \eta)$ are the shape function associated with node $i^{t h}$ in terms of natural coordinates.

When folded plates are considered, the membrane and bending terms are coupled, as can be clearly seen in Fig.1. Even more, since the rotations of the normal appear as unknowns for the ReissnerMindlin model, so that, a new unknown for the inplane rotation $\left(\theta_{\mathrm{z}}\right)$ is inserted as a virtual parameter.

$$
\left\{\begin{array}{c}
u \\
v \\
w \\
\theta_{x} \\
\theta_{y} \\
\theta_{z}
\end{array}\right\}_{e}=\left[\begin{array}{cccccc}
l_{x^{\prime} x} & l_{y^{\prime} x} & l_{z^{\prime} x} & 0 & 0 & 0 \\
l_{x^{\prime} y} & l_{y^{\prime} y} & l_{z^{\prime} y} & 0 & 0 & 0 \\
l_{x^{\prime} z} & l_{y^{\prime} z} & l_{z^{\prime} z} & 0 & 0 & 0 \\
0 & 0 & 0 & l_{y^{\prime} y} & -l_{x^{\prime} y} & l_{z^{\prime} y} \\
0 & 0 & 0 & -l_{y^{\prime} x} & l_{x^{\prime} x} & -l_{z^{\prime} x} \\
0 & 0 & 0 & l_{y^{\prime} z} & -l_{x^{\prime} z} & l_{z^{\prime} z}
\end{array}\right]\left\{\begin{array}{c}
u^{\prime} \\
v^{\prime} \\
w^{\prime} \\
\theta_{x}^{\prime} \\
\theta_{y}^{\prime} \\
\theta_{z}^{\prime}
\end{array}\right\}_{e}
$$

where: $l_{\mathrm{ij}}$ are the direction cosines between the global and local coordinates.

\subsection{Procedure for failure analysis}

The finite-element procedure described in the preceding section can be used to determine the stresses in the laminate coordinates at any point of all the individual folded laminates plate. Since the failure criteria described earlier require the stresses with respect to the material coordinates of each lamina, a transformation of the stresses from laminate coordinates to the lamina material coordinates is required.

The stresses in material coordinates can be determined in the way: compute stresses using the lamina constitutive equations with stiffness referred to the laminate coordinates and then transform laminate stresses to lamina stresses.

The lamina stresses then used in a chosen failure criterion to check if each lamina has failed. If the failure criterion is satisfied in a ply of an element, then the individual contributions, called failure indices, of each stress component to the tensor polynomial are computed. 
The failure load calculation according to the Tsai-Wu and maximum stress criteria were used in this study.

\subsubsection{Maximum stress criterion}

In the maximum stress criterion [7], failure of any composite layer is assumed to occur if any one of the following conditions is satisfied:

$$
\sigma_{1}>X_{T} ; \sigma_{2}>Y_{T} ; \sigma_{4}>R ; \sigma_{5}>S ; \sigma_{6}>T
$$

where: $\sigma_{1}, \sigma_{2}$ are the normal stress components, $\sigma_{4}$, $\sigma_{5}$ and $\sigma_{6}$ are shear stress components, $X_{T}, Y_{T}$ are the lamina normal strengths in the 1, 2 directions and $R, S$ and $T$ are the shear strengths in the 23,13 and 12 local planes, respectively.

when $\sigma_{1}, \sigma_{2}$ are of a compressive nature they should be compared with $X_{C}, Y_{C}$, which are normal strengths in compression along with the 1, 2 directions, respectively.

\subsubsection{The Tsai-Wu criterion}

The Tsai-Wu failure criterion of a composite layer [7] is assumed to occur if the following condition is satisfied:

$$
\begin{aligned}
& F_{1} \sigma_{1}+F_{2} \sigma_{2}+F_{3} \sigma_{3}+2 F_{12} \sigma_{1} \sigma_{2}+2 F_{13} \sigma_{1} \sigma_{3}+ \\
& +2 F_{23} \sigma_{2} \sigma_{3}+F_{11} \sigma_{1}^{2}+F_{22} \sigma_{2}^{2}+F_{33} \sigma_{3}^{2}+F_{44} \sigma_{4}^{2}+ \\
& +F_{55} \sigma_{5}^{2}+F_{66} \sigma_{6}^{2} \geq 1
\end{aligned}
$$

where

$$
\begin{aligned}
& F_{1}=\frac{1}{X_{T}}-\frac{1}{X_{C}} ; F_{2}=\frac{1}{Y_{T}}-\frac{1}{Y_{C}} ; F_{3}=\frac{1}{Z_{T}}-\frac{1}{Z_{C}} ; \\
& F_{11}=\frac{1}{X_{T} X_{C}} ; F_{22}=\frac{1}{Y_{T} Y_{C}} ; F_{33}=\frac{1}{Z_{T} Z_{C}} ; F_{44}=\frac{1}{R^{2}} ; \\
& F_{55}=\frac{1}{S^{2}} ; F_{66}=\frac{1}{T^{2}} ; F_{12}=-\frac{1}{2} \sqrt{\frac{1}{X_{T} X_{C} Y_{T} Y_{C}}} ; \\
& F_{13}=-\frac{1}{2} \sqrt{\frac{1}{X_{T} X_{C} Z_{T} Z_{C}}} ; F_{23}=-\frac{1}{2} \sqrt{\frac{1}{Y_{T} Y_{C} Z_{T} Z_{C}}}
\end{aligned}
$$

A flow chart of the procedure is given in Fig.2.

\section{Results}

\subsection{Validation Example}

In order to verify the present model, the folded plate given by Peng et al. [6] is recalculated. The folded plate is built up by three identical square flat plates and clamped on one side. The flat plates are vertical to each other along the joints of the folded plate (show in Fig. 3).
Define the initial and increment load $\mathrm{P}_{0}$ and $\Delta \mathrm{P}$

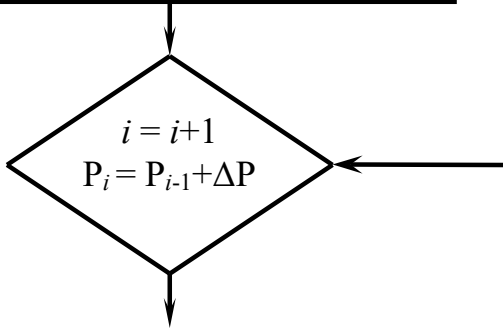

Calculate the nodal displacement
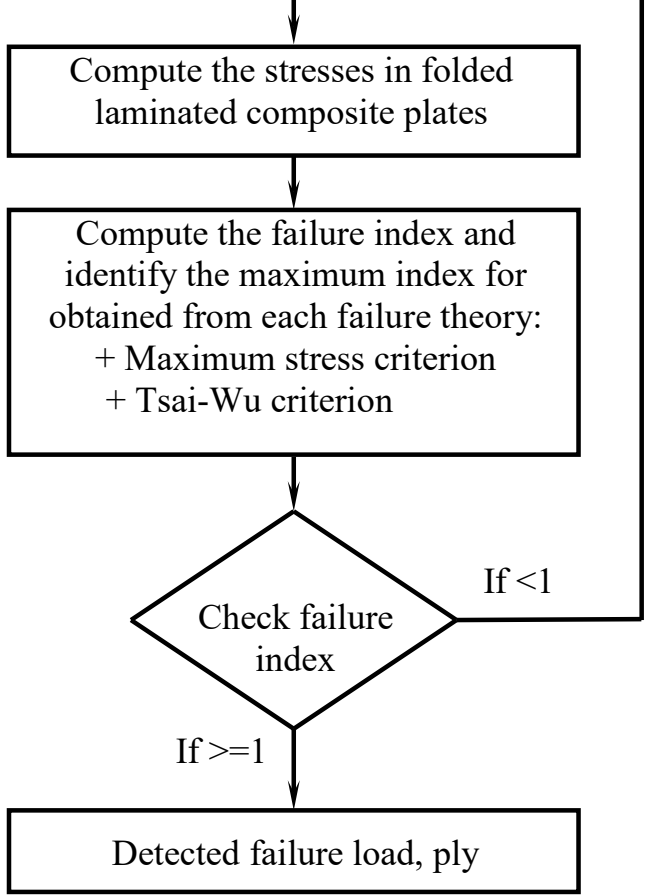

Fig. 2. A flow chart of the computation procedure used to determine the failure loads

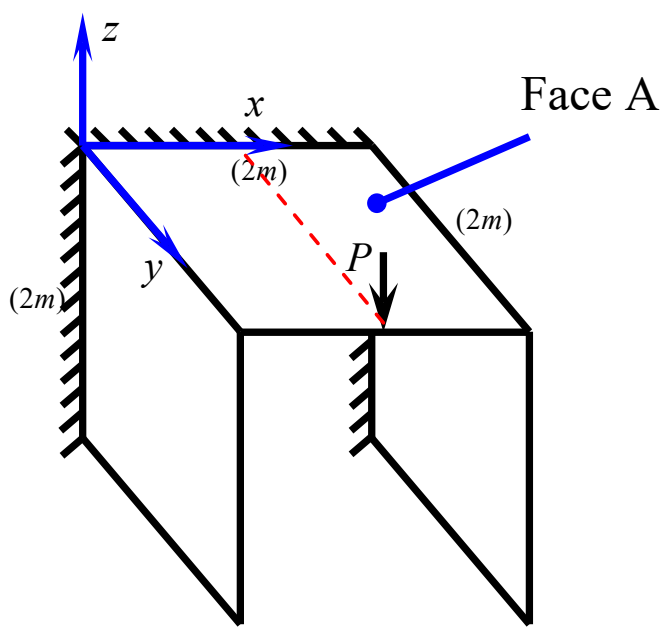

Fig. 3. A cantilevered two folded plate 
Young's modulus and Poisson's ratio of the plates are $E=3.10^{7} \mathrm{~Pa}$ and $v=0.3$, respectively. A concentrated load of $P=0.1(\mathrm{~N})$ is applied to point $(2,1,0)$, towards the negative direction of the $\mathrm{z}$-axis.

The deflections along $x=1 \mathrm{~m}$ of flat plate A, calculated by the proposed method and Peng et al. [6] are listed in Table 1. The agreement between the two sets of results is good.

Table 1. Deflections $\left(* 10^{-7} \mathrm{~m}\right)$ along $\mathrm{x}=1(\mathrm{~m})$

\begin{tabular}{|c|c|c|}
\hline Distance (m) & Present & Peng et al. [6] \\
\hline $\mathrm{y}=0$ & 0 & 0 \\
\hline$y=0.5$ & -0.02492 & -0.02489 \\
\hline$y=1$ & -0.09625 & -0.09491 \\
\hline$y=1.5$ & -0.23667 & -0.22959 \\
\hline$y=2$ & -0.50547 & -0.48446 \\
\hline
\end{tabular}

In the following subsections, we will analysis of several folded composite plates

\subsection{Determination of stresses and bending failure load}

\subsubsection{Hat-type folded composite plate}

In this section, hat type folded composite plates were considered (Fig.4) to investigate the effects of folding angle $(\alpha)$ on stresses and failure load. Geometric parameters of the plate: $L_{1}=0.25 \mathrm{~m}$; $L_{2}=0.2 \mathrm{~m} ; \quad L_{3}=0.3 \mathrm{~m} ; \quad W=0.8 \mathrm{~m}$, total thickness $t=0.02 \mathrm{~m}$, and folding angle $\alpha$ is $\left(90^{\circ}, 120^{\circ}\right.$ and $\left.150^{\circ}\right)$.

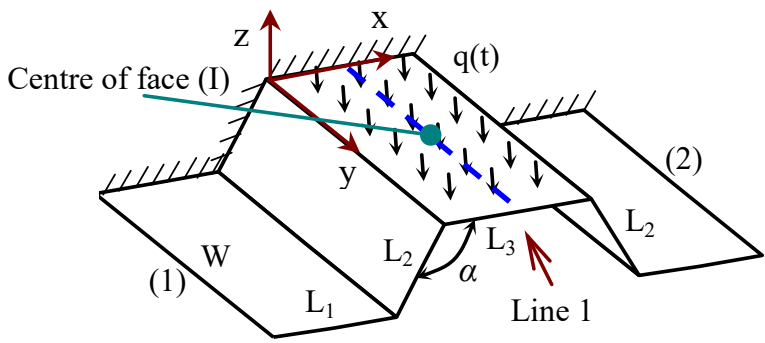

Fig. 4. Multi-folding composite plates subjected to uniformly distributed load intensity $\mathrm{q}_{0}$.

The following material property has been used for all composite folded plates in numerical analyses, the $T 300 / 5208$ graphite-epoxy material:

- Material properties:

$E_{1}=132.4 \mathrm{GPa} ; E_{2}=E_{3}=10.7 \mathrm{GPa} ; G_{12}=G_{13}$ $=5.6 \mathrm{GPa} ; G_{23}=3.4 \mathrm{GPa} ; v_{12}=v_{13}=0.24 ; v_{23}=0.49$.
- Strength properties: $X_{\mathrm{T}}=1514,0 \mathrm{MPa}$; $X_{\mathrm{C}}=1996.7 \mathrm{MPa} ; Y_{\mathrm{C}}=Y_{T}=43.8 \mathrm{MPa}$; $S=T=87.0 \mathrm{MPa} ; R=68.0 \mathrm{MPa}$.

The boundary conditions are given in Fig.4:

+ Case 1: one end is clamped (at $y=0$ )

+ Case 2: two ends are clamped (at $y=0$ and $y=L$ )

+ Case 3: two opposite edges are clamped.

\subsubsection{Convergence study}

To investigate the convergence, the cantilever plate having four layers $\left[0^{\circ} / 90^{\circ} / 90^{\circ} / 0^{\circ}\right]$ subjected to uniformly distributed load of density $q_{0}=10^{4}\left(\mathrm{~N} / \mathrm{m}^{2}\right)$ on the top surface (I) is used as shown in Fig.4 for difference of folding angle $\alpha$. The results are listed in Table 2. It is shown that with a mesh of 160 elements, the center deflections of plates are converged.

Table 2. Comparison of deflection $(w)$ at center points for convergence study

\begin{tabular}{|c|c|c|c|}
\hline \multirow{2}{*}{$\begin{array}{c}\text { Number } \\
\text { of } \\
\text { elements }\end{array}$} & \multicolumn{3}{|c|}{ Center deflections, $w(\mathrm{~mm})$} \\
\cline { 2 - 4 } & $\alpha=90^{0}$ & $\alpha=120^{0}$ & $\alpha=150^{\circ}$ \\
\hline 66 & -0.032142 & -0.040723 & -0.098467 \\
\hline 160 & -0.031381 & -0.039276 & -0.097822 \\
\hline 264 & -0.031312 & -0.039217 & -0.097765 \\
\hline
\end{tabular}

Therefore, in the following studies, the plate is divided by 160 eight-nodded isoparametric rectangular elements.

\subsubsection{Effect of folding angle $\alpha$ on stresses.}

To investigate the effect of folding angle on stresses, hat type folded plates are subjected to uniformly distributed load of density $\mathrm{q}_{0}=10^{4}\left(\mathrm{~N} / \mathrm{m}^{2}\right)$ on the top surface (I). The two ends of plates are clamped; and the folding angle $\alpha$ is $90^{\circ}, 120^{\circ}$ and $150^{\circ}$, respectively; the plates consist of four layers, $\left[0^{0} / 90^{\circ} / 90^{\circ} / 0^{0}\right]$.

The stresses $\left(\sigma_{x}, \sigma_{y}\right)$ through the thickness are calculated at the center point of the face (I) and presented in Fig.5 and Fig.6, respectively.

It can be observed that all the stresses for the $90^{\circ}$ and $120^{\circ}$ folding angles are close to each other, the stresses $\left(\sigma_{x}, \sigma_{y}, \sigma_{x y}\right)$ increased when the folding angle decreased from $90^{\circ}$ to $150^{\circ}$ but not much.

The stresses $\left(\sigma_{x}, \sigma_{y}, \sigma_{x y}\right)$ and $\left(\sigma_{x z}, \sigma_{y z}\right)$ through the thickness are presented in Fig. 5 have been compared with various folding angle. 


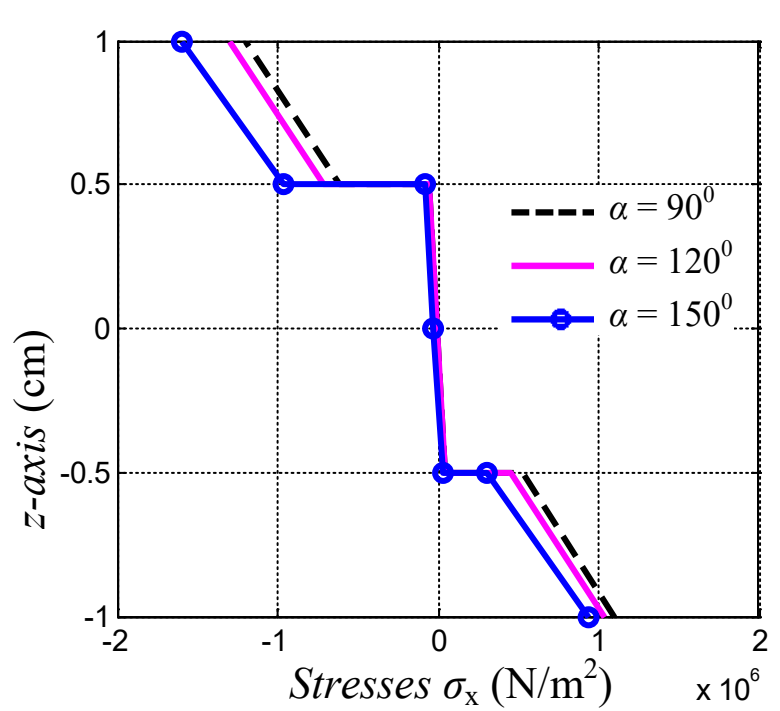

Fig. 5. $\sigma_{\mathrm{x}}\left(\alpha=\left(90^{0}, 120^{\circ}, 150^{\circ}\right)\right)$ through the thickness

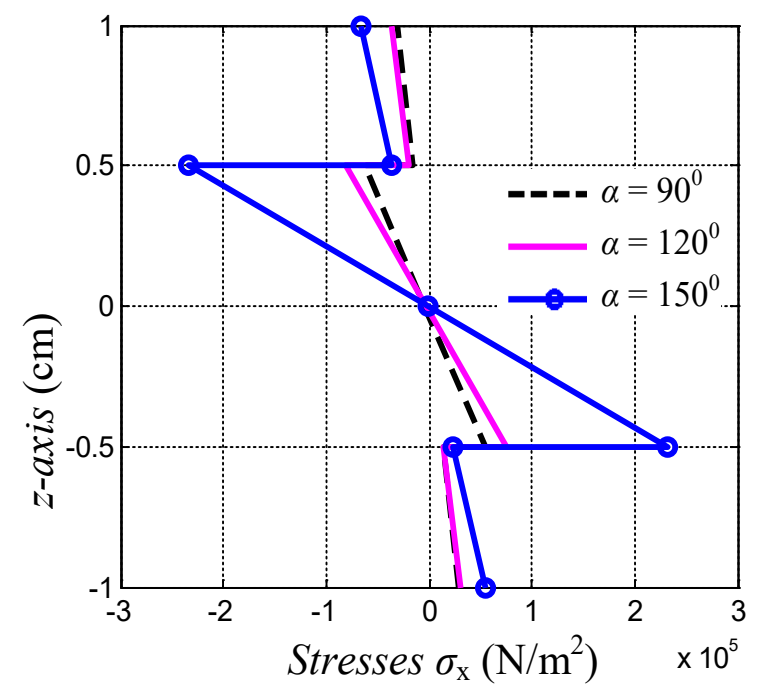

Fig. 6. $\sigma_{\mathrm{y}}\left(\alpha=\left(90^{0}, 120^{\circ}, 150^{\circ}\right)\right)$ through the thickness

The stress $\sigma_{\mathrm{x}}$ and stress $\sigma_{\mathrm{y}}$ on the surface of the plate along y-axis (Line 1) are presented in Fig.7 and Fig.8, respectively.

From Fig.7 and Fig. 8 we can see that the stresses for the folding angle of $150^{\circ}$ are higher than the others.

\subsubsection{Effects of folding angle $\alpha$ and boundary conditions on failure load.}

In order to investigate the effects of folding angle and boundary conditions on the failure load, the same plate has eight layers $\left[60^{\circ} /-60^{\circ} / 60^{\circ} /-60^{0}\right]_{s}$ subjected to uniformly distributed load on top of one individual plate (Fig.4) have been considered. The

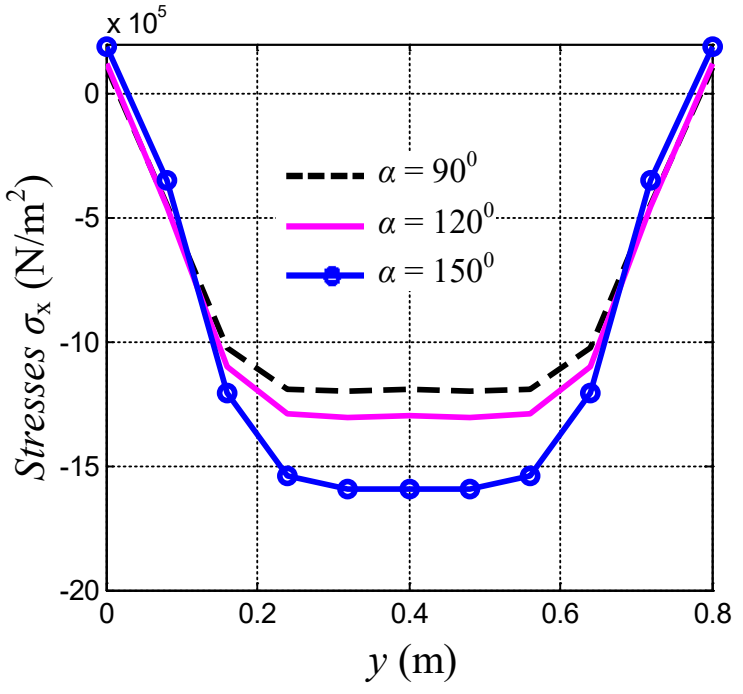

Fig. 7. Comparison of $\sigma_{\mathrm{x}}$ along $\mathrm{y}$-axis

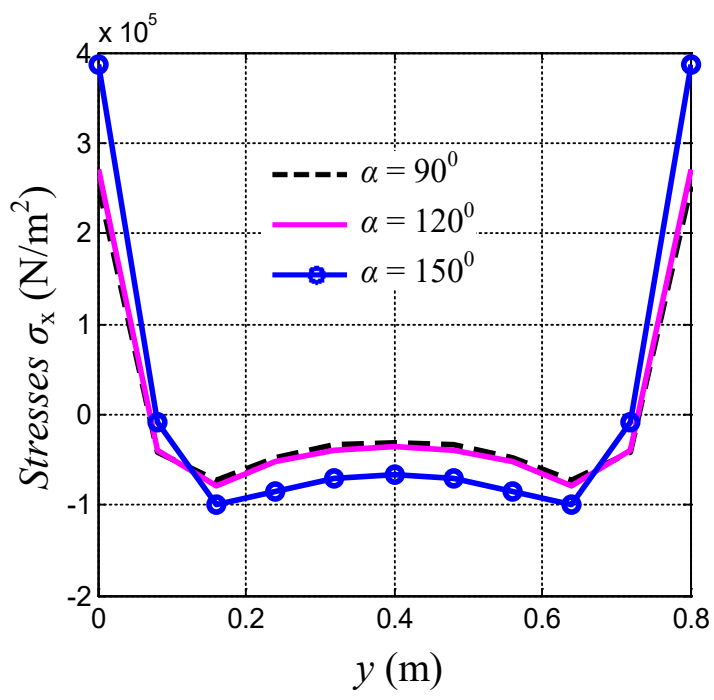

Fig. 8. Comparison of $\sigma_{\mathrm{x}}$ along $\mathrm{y}$-axis

Tsai-Wu and maximum stress failure criteria are used in the analysis. The failure loads are reported in Table 3 and Table 4 for various folding angle $\alpha=90^{\circ}, 120^{\circ}$, and $150^{\circ}$.

From Tables 3 and 4, we can see that for all laminated composite plates considered here, the failure occurred in the top layer. The location of failure in the plate also varies depending on the failure criterion used, boundary conditions, and folding angles. For example, for a folding plate with $\alpha=120^{\circ}$ and let us consider case 1 , according to the Tsai-Wu criterion, the failure occurs at point 1 (Fig.9), while, according to the maximum stress failure criterion, the failure happens at point 3 . 
Table 3. Failure loads $\left(\mathrm{N} / \mathrm{m}^{2}\right)$ according to Tsai- $\mathrm{Wu}$ failure criterion of hat-type folded laminate composite plate under uniformly distributed load.

\begin{tabular}{|c|c|c|c|}
\hline \multirow{2}{*}{$\begin{array}{l}\text { Folding } \\
\text { angle } \alpha\end{array}$} & \multicolumn{3}{|c|}{ Tsai- Wu criterion } \\
\hline & Case 1 & Case 2 & Case 3 \\
\hline$\alpha=90^{0}$ & $\begin{array}{c}951125 \\
* \text { (Point 1) }\end{array}$ & $\begin{array}{r}1409045 \\
* \text { (Point 2) }\end{array}$ & $\begin{array}{c}269285 \\
* \text { (Point 4) }\end{array}$ \\
\hline$\alpha=120^{\circ}$ & $\begin{array}{c}895815 \\
* \text { (Point 1) }\end{array}$ & $\begin{array}{r}1308135 \\
* \text { (Point 2) }\end{array}$ & $\begin{array}{c}269815 \\
* \text { (Point 5) }\end{array}$ \\
\hline$\alpha=150^{\circ}$ & $\begin{array}{c}787115 \\
* \text { (Point 1) }\end{array}$ & $\begin{array}{r}1138015 \\
* \text { (Point 2) }\end{array}$ & $\begin{array}{c}270115 \\
* \text { (Point 5) }\end{array}$ \\
\hline
\end{tabular}

(*): Failure location appeared in the $8^{\text {th }}$ layer.

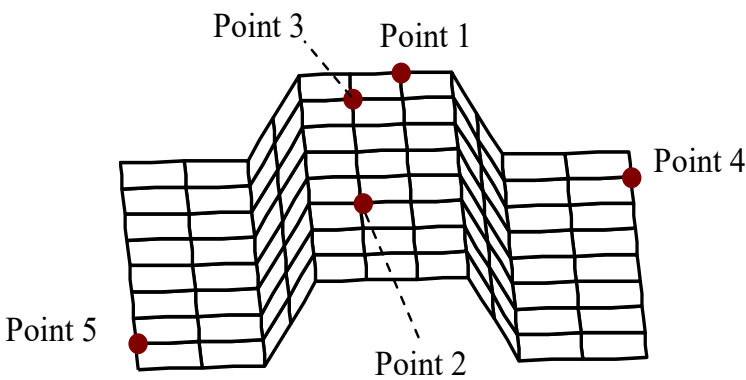

Fig. 9. Failure locations

For case 2, according to the two above failure criteria, for all plates with various folding angle $\alpha$, the failure locations are the same, at point 2 . For case 3 , with folding angle $\alpha=90^{\circ}$, failure location occurred at point 4 according to both failure criteria, and failure location happened at point 5 for $\alpha=120^{\circ}, 150^{\circ}$.

\section{Conclusion}

In the present study, based on the first-order shear deformation theory, a finite element algorithm and home-made Matlab computer code have been developed to analyse the stresses of folded composite plates under bending loads. For the first time, according to Tsai-Wu and maximum stress failure criteria, the failure bending loads and failure locations of some folded composite plates are determined. The effects of folding angle, boundary conditions on the stresses and failure bending loads are examined and discussed in detail. These new results are tabulated and illustrated in various figures and show that:

- The folding angle influenced considerably the stresses in folded composite plates.

- The location of failure in the folded composite plate depends on the failure criterion used, boundary conditions and folding angles.
Table 4. Failure loads $\left(\mathrm{N} / \mathrm{m}^{2}\right)$ according to maximum stress failure criterion of hat-type folded laminate composite plate under uniformly distributed load.

\begin{tabular}{|c|c|c|c|}
\hline \multirow{2}{*}{$\begin{array}{c}\text { Folding } \\
\text { angle } \alpha\end{array}$} & \multicolumn{3}{|c|}{ Maximum stress criterion } \\
\cline { 2 - 4 } & Case 1 & Case 2 & Case 3 \\
\hline$\alpha=90^{\circ}$ & $\begin{array}{c}1032235 \\
*(\text { Point } 1)\end{array}$ & $\begin{array}{c}1358965 \\
*(\text { Point } 2)\end{array}$ & $\begin{array}{c}272185 \\
*(\text { Point 4) }\end{array}$ \\
\hline$\alpha=120^{\circ}$ & $\begin{array}{c}968055 \\
*(\text { Point 3) }\end{array}$ & $\begin{array}{c}\text { *(Point 2) } \\
\text { (264815 }\end{array}$ & $\begin{array}{c}272705 \\
*(\text { Point 5) }\end{array}$ \\
\hline$\alpha=150^{\circ}$ & $\begin{array}{c}844675 \\
*(\text { Point 3) }\end{array}$ & $\begin{array}{c}1100125 \\
\text { (Point 2) }\end{array}$ & $\begin{array}{c}\text { 273045 } \\
\text { (Point 5) }\end{array}$ \\
\hline
\end{tabular}

(*): Failure location appeared in the $8^{\text {th }}$ layer.

The result of this study will serve as a benchmark for future research for designing folded composite structures and sandwich structures made of composite materials.

\section{References}

[1] P.B. Yoseph and I. Hersckovitz, Analysis of Folded Plate Structures, Thin-Walled Structures 7 (1989) 139-158.

[2] A. Samanta and M. Mukhopadhyay, Finite element static and dynamic analyses of folded plates, Engineering Structures 21 (1999) 277-287.

[3] Y. Lai and W. Yu, Analytical solution for forced vibration of a simply-supported $\mathrm{V}$-shaped folded plate roof, Thin-Walled Structures 40 (2002) 215-223.

[4] E. Hernández and L.H. Nieto, Finite element approximation of free vibration of folded plates, Computer Methods in Applied Mechanics and Engineering 198 (2009) 1360-1367.

[5] S. Haldar, A.H. Sheikh, Free vibration analysis of isotropic and composite folded plates using a shear flexible element, Finite Elem. Anal. Des. 42 (2005) 208-226.

[6] L.X. Peng, S. Kitipornchai, K.M. Liew, Bending analysis of folded plates by the FSDT meshless method, Thin-Walled Structures, Vol 44 (2006) 11381160 .

[7] J.N. Reddy and A.K. Pandey, A first-ply failure analysis of composite laminates, Computer and structure 25 (1987) 371-393.

[8] A. Ghosh and D. Chakravorty, Failure Analysis of Civil Engineering Composite Shell Roofs, Procedia Engineering 173 (2017) 1642 - 1649.

[9] X. Chen, J. Tang, K. Yang, Modeling multiple failures of composite box beams used in wind turbine blades, Composite Structures 217 (2019) 130-142. 
[10] M. Meng, H.R. Le, M.J. Rizvi, S.M. Grove, 3D FEA modelling of laminated composites in bending and their failure mechanisms, Composite Structures 119 (2015) 693-708.

[11] D. Deland , Z. Zhang, K. Kirane, Biaxial flexural failure of woven composite plates investigated by the ring on ring bending test, Thin-Walled Structures 148 (2020) 106585.
[12] Y. Sun, L. Guo, T. Wang, L. Yao, X. Sun, Bending strength and failure of single-layer and double-layer sandwich structure with graded truss core, Composite Structures 226 (2019) 111204.

[13] K.J. Bathe, Finite element procedures, Prentice-Hall, Inc (1996).

[14] Tran Ich Thinh, Composite Materials, Viet Nam Education Publishing House (1994) (in Vietnamese) 